\title{
Evidence for dissolution of fatty acids in sediment traps: Impact on flux estimates
}

\author{
Arne Körtzinger, Detlef E. Schulz-Bull, Gert Petrick, and Jan C. Duinker \\ Department of Marine Chemistry, Institute for Marine Research at the University of Kiel, Kiel, Germany
}

\begin{abstract}
The effect of dissolution from particulates into the supernatant solution in sediment trap sample cups has been measured for fatty acids. A mooring array with time series sediment traps was deployed in the northeast Atlantic Ocean $\left(59^{\circ} \mathrm{N}, 21^{\circ} \mathrm{W}\right)$ for 14 months. Selected representative samples from the trap at $2200 \mathrm{~m}$ (poisoned with $\mathrm{NaN}_{3}$ ) were analyzed for total and free fatty acids in both the solution and particulate phase by means of gas chromatography-mass spectrometry with an ion trap detector. The flux contribution of the dissolved total fatty acids ( $\Sigma$ DTFA) was found to be between 15 and $75 \%$ of the total flux ( $\Sigma$ TTFA, sum of the fluxes of total fatty acids in both particles and supernatants). Dissolved free fatty acids ( $\sum$ DFFA) represented 25$88 \%$ of the total flux of free fatty acids ( $\Sigma$ TFFA). Absolute concentrations of total and free fatty acids in both compartments are discussed in terms of the processes controlling the distribution between the two phases, for example, readsorption. Sample handling, poisoning, bacterial activity, and swimmers may also affect fatty acid distribution. Flux data (sum of particulate and dissolved fluxes) are presented for individual fatty acids. Also, the degree of dissolution of individual fatty acids is shown for one sample (dissolved fraction ranging between 16 and $98 \%$ of total flux).
\end{abstract}

\section{Introduction}

Knowledge of the seasonal and interannual variability in sedimentation rates and of transformation processes in the water column is crucial for understanding the ocean's role in global biogeochemical cycles. Sediment traps have been used successfully to estimate mass fluxes. Their use has also permitted observations of degradation processes in the water column [Honjo et al., 1982; Wakeham et al., 1984; Wakeham and Canuel, 1988; Wakeham and Lee, 1989]. The quantitative assessment of biogeochemical fluxes is among the most important applications of sediment traps in studies such as the Joint Global Ocean Flux Study (JGOFS). Biomarker substances like fatty acids have proven to be important tools for providing additional information on sources and fates of organic components of sinking material [Perry et al., 1979; Volkman et al., 1980; De Baar et al., 1983; Sicre et al., 1988; Currie and Johns, 1988; Mayzaud et al., 1989; Wakeham and Beier, 1991].

All data derived from sediment trap applications are subject to various effects that may bias flux determination. The collection efficiency depends on flow conditions [Butman et al., 1986; Baker et al., 1988; Gust et al., 1992], on tilt [Gardner, 1985], and on trap design (funnel type, cylinder type, etc.) [Honjo et al., 1992]. The problem of zooplankton "swimmers," especially of cryptic swimmers, which actively enter the traps, has been discussed extensively [Michaels et al., 1990; Lee et al., 1992], and no final solution is in sight. In situ effects of preservatives and biocides on the organic matrix collected with sediment traps have been reported [Knauer et al., 1984; Gundersen and Wassmann, 1990; Lee et al., 1992]. Despite all these problems, sediment

Copyright 1994 by the American Geophysical Union.

Paper number 93JC02784.

0148-0227/94/93JC-02784\$05.00 traps are still the most important tool for obtaining particle flux data in the open ocean.

A phenomenon that has sometimes been overlooked in sediment trap work is the loss of material by partial dissolution of the organic matrix into the supernatant. Cell autolysis and microbial degradation occur under certain conditions, affecting in particular long-term moorings. Poisoning of sampling cups cannot completely prevent degradation of the organic matter [Gardner et al., 1983]. Samples, when no longer exposed to the collecting funnel, may not be separated hermetically from the surrounding water. Dissolution and diffusion out of the cups may occur if the sample cup cups are not sufficiently sealed from the surrounding water. Only if significant loss of dissolved species through sample seals can be excluded can the determination of parameters in both particles and supernatants provide reliable data.

The Kiel sediment trap has been developed at the Institute for Marine Research in Kiel with this aim in mind. It was shown to be leakproof during drift experiments in the North Atlantic Ocean [Duinker and Kremling, 1990]. This trap design may therefore allow accurate determination of fluxes by analysis of both particles and supernatants.

\section{Materials and Methods}

\section{Materials}

Fatty acid standards were obtained from Larodan Fine Chemicals AB (Malmö, Sweden). Potassium hydroxide pellets p.a. (pro analysi; analytical grade), hydrochloric acid $32 \%$ p.a., and nitric acid $65 \%$ p.a. were purchased from Merck (Darmstadt, Germany), and N-methyl-tertbutyldimethylsilyltrifluoroacetamide (MTBSTFA) was obtained from Macherey-Nagel (Düren, Germany). All solvents (dichloromethane, methanol, $n$-hexane; Merck) were 
of analytical grade and redistilled over a $1.5-\mathrm{m}$ column packed with Raschig rings. All glassware was cleaned with detergent solution (Mucasol@, Merz \& Co., Frankfurt, Germany), rinsed thoroughly with hot water and deionized water and then heated to $250^{\circ} \mathrm{C}$ for 12 hours.

\section{Sampling and Sample Preparation}

A deep-sea array with time series sediment traps (Kiel sediment trap, Salzgitter Elektronik, Germany) was moored in the northeast Atlantic Ocean $\left(58^{\circ} 59.2^{\prime} \mathrm{N}, 21^{\circ} 01.4^{\prime} \mathrm{W}\right)$ at a water depth of $2880 \mathrm{~m}$ in June 1989. All parts of the sediment traps (baffle, funnel, revolving unit, and cups) went through a cleaning procedure with detergent solution, $1 \%$ nitric acid, $1 \%$ hydrochloric acid, and deionized water, followed by in situ conditioning (equilibration with seawater) for 2 weeks. The mooring was recovered in August 1990.

The choice of biocide (e.g., $\mathrm{HgCl}_{2}$ and $\mathrm{NaN}_{3}$ ) or preservative (e.g., formaldehyde and glutaraldehyde) in the seawater-based medium in the trap cups was limited owing to the species which were planned to be analyzed. $\mathrm{HgCl}_{2}$ had to be excluded because of interference with trace element analysis. Formaldehyde and glutaraldehyde are known to alter the sample chemically [Knauer and Asper, 1989], therefore potentially interfering in the analysis of trace organics and biomarkers. The additive used for this experiment was $\mathrm{NaN}_{3}$ at a final concentration of $0.5 \%$. The medium was adjusted to a density larger than that of the surrounding water, by addition of precombusted $\mathrm{NaCl}$ to in situ seawater up to a final salt concentration of $41 \mathrm{psu}$ (before addition of biocide). In situ seawater was taken with $30-\mathrm{L}$ Goflo water samplers which had been precleaned with the same cleaning procedure.

The deepest sediment trap at $2200 \mathrm{~m}$ was chosen for this investigation to reduce the collection of swimmers which tend to disintegrate in traps that are not preserved but only poisoned (e.g., $\mathrm{NaN}_{3}$ ), thus affecting biomarker patterns. From the selected samples, only sample 9 contained a fairly well preserved visible swimmer (amphipod), which was removed before sample processing.

Upon recovery, samples were stored at $4^{\circ} \mathrm{C}$ until further processing. A rotary splitter was not used because of leaching and contamination of trace element analysis. The comparatively large volume of water required by the rotary splitting procedure may affect the equilibrium between particles and supernatant solution and may also additionally leach the particulate matter. Instead, supernatants and particles were separated by centrifugation $(30 \mathrm{~min}, 5000 \mathrm{rpm})$. Centrifugation was preferred to filtration because the process of filtration has been reported to release more labile material than does centrifugation [Collier and Edmond, 1984]. Wet particle samples were homogenized and split by weight. Particulate splits and supernatants were stored again at $4^{\circ} \mathrm{C}$ until further processing.

\section{Extraction and Derivatization}

The lipid fraction of wet particle splits was extracted ultrasonically with boiling $\mathrm{CH}_{2} \mathrm{Cl}_{2}\left(40^{\circ} \mathrm{C}\right)$ in a nitrogen atmosphere for 2 hours. Extraction was repeated twice for quantitative extraction. Supernatants were extracted three times with $\mathrm{CH}_{2} \mathrm{Cl}_{2}$ using a separatory funnel. Combined extracts of particles and supernatants were stored under nitrogen in glass ampoules.

Total fatty acid analysis was carried out by saponifying an aliquot with $1 N \mathrm{KOH}$ in methanol/water $(1: 1, \mathrm{v}: \mathrm{v})$ at $100^{\circ} \mathrm{C}$ (4 hours in glass ampoules under nitrogen) after the organic solvent had been removed in a gentle stream of nitrogen. The aqueous solution of fatty acid carboxylates was acidified with $4 \mathrm{~N} \mathrm{HCl}$ to $p \mathrm{H} \mathrm{1-2.} \mathrm{Fatty} \mathrm{acids} \mathrm{were} \mathrm{then}$ reextracted with $n$-hexane.

Free fatty acids were extracted as carboxylates with $1 \mathrm{~N}$ $\mathrm{KOH}$ in methanol/water $(1: 1, \mathrm{v}: \mathrm{v})$ from another aliquot. This was carried out at room temperature to avoid saponification of naturally occurring fatty acid derivatives. After removal of the organic phase and acidification of the aqueous solution to $p \mathrm{H} 1-2$, fatty acids were reextracted with $n$-hexane.

For mass spectrometric identification and quantification, fatty acids were derivatized with MTBSTFA as tertbutyldimethylsilyl derivatives (TBDMS).

\section{Gas Chromatography-Mass Spectrometry}

Gas chromatography (GC)-mass spectrometry was performed with a Carlo Erba 6000 Vega series 2 gas chromatograph, using a methyl silicone 400 fused-silica capillary column ( $15 \mathrm{~m} \times 0.25 \mathrm{~mm}$ ID, Quadrex) in connection with a Finnigan MAT ion trap detector 800 (ITD-MS). GC conditions were carrier gas hydrogen at $2 \mathrm{~mL} \mathrm{~min}^{-1}$ (specification 99.999\%), on-column injector; temperature programming was $1 \mathrm{~min}$ isothermal at $60^{\circ} \mathrm{C}, 4^{\circ} \mathrm{C} \mathrm{min}^{-1}$ to $320^{\circ} \mathrm{C}, 5 \mathrm{~min}$ isothermal; transfer line temperature was $280^{\circ} \mathrm{C}$.

Mass spectrometry was performed with electron impact ionization. The ion trap manifold was operated at $220^{\circ} \mathrm{C}$. The mass scanning rate in full-scan mode from 50 to $600 \mathrm{amu}$ was $1.0 \mathrm{~s} \mathrm{scan}^{-1}$.

\section{Identification and Quantification}

TBDMS derivatives of fatty acids show very characteristic electron impact mass spectra with molecular ions (M) and M-15 ions of low abundance, but very intense M-57 ions due to loss of the tert-butyl group from the molecular ion [Kim et al., 1989]. M-57 ions constitute the base peaks for most saturated and monounsaturated fatty acids, enabling rapid and unambiguous identification. With increasing number of double bonds in the molecule, mass spectra are less interpretable; i.e., they show low intensities or absence of interpretable fragments and prominent ions. Branched-chain fatty acids show fragmentation patterns almost identical to that of unbranched $n$ isomers. These compounds were distinguished therefore by comparing retention times with those of standards.

Chromatographic conditions did not allow separation of all fatty acids, e.g., coelution of 18:1 isomers and of 18:2 with 18:3 isomers was observed. For the quantification of coeluting components and components present at low concentrations in the presence of unknown substances at similar retention times, quantification was performed on the basis of single mass chromatograms of the M-57 ions rather than on the basis of total ion chromatograms. Coeluting 18:1, 18:2, and 18:3 fatty acids could thus be separated and quantified accurately. For external standard quantification, calibration curves with at least three and in most cases 5 data points (from $100 \mathrm{pg}$ to $30 \mathrm{ng}$ ), were established. Sample extracts were concentrated or diluted to fit into this concentration range. Injection volume was 1 to $2 \mu \mathrm{L}$. Fatty acid content from blank analyses showed negligible contamination for all compounds studied. 


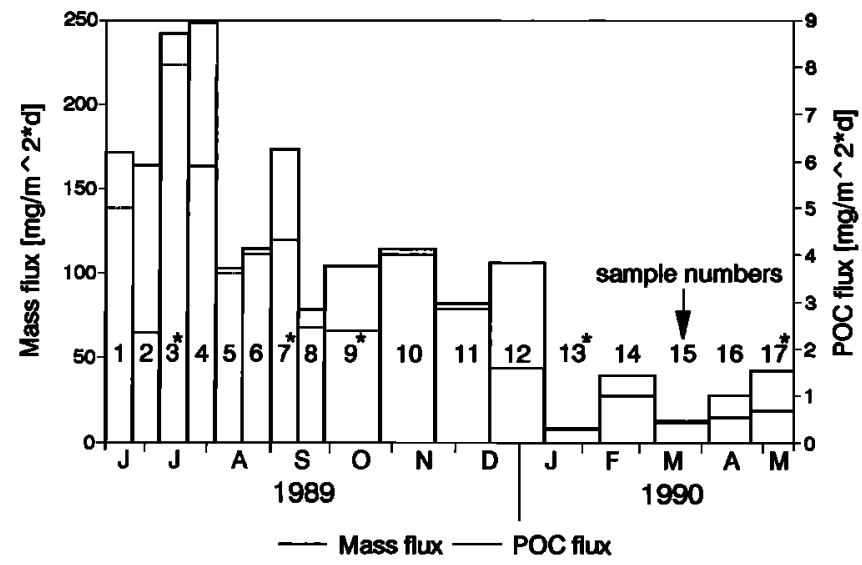

Figure 1. Mass flux and POC flux, in milligrams per square meter per day, at mooring position $58^{\circ} 59.2^{\prime} \mathrm{N}, 21^{\circ} 01.4^{\prime} \mathrm{W}$ at $2200 \mathrm{~m}$ depth. Bar widths indicate the exposition time of samples. Marked samples were selected for the present report on free and total fatty acids in particles and supernatants.

Analysis of free and total fatty acids was carried out for both particles and supernatants. Data are given for both compartments to demonstrate the problem of dissolution. The following abbreviations will be used: PTFA, particulate total fatty acids; DTFA, dissolved total fatty acids; PFFA, particulate free fatty acids; and DFFA, dissolved free fatty acids. Relevant flux values were calculated as the sum of both compartments and are denoted TTFA, or total fatty acids (PTFA + DTFA), and TFFA, or total free fatty acids (PFFA + DFFA).

For individual fatty acid constituents we use the shorthand notation $X: Y \omega Z$, with $X$ specifying the number of carbon atoms and $Y$ the number of double bonds. $Z$ denotes the position of the first double bond relative to the terminal methyl group.

\section{Limitations}

The presence of more than two double bonds prohibits the practical interpretation of ITD-MS spectra of polyunsaturated fatty acids: quantification by $\mathrm{M}-57$ ions is therefore limited to fatty acids with 0 to 2 double bonds. Two groups of fatty acid isomers with three double bonds (18:3 and 20:3) could be quantified only in samples where the concentrations were high enough. Cis/trans isomers and positional isomers could not be distinguished and had to be quantified as group parameters.

The detection limit was in the order of $100 \mathrm{pg}$ per injection for each saturated or monounsaturated component and $1 \mathrm{ng}$ per injection for fatty acids with two double bonds.

\section{Results and Discussion}

Results are presented for the sediment trap at 2200-m depth. The fluxes of total mass (dry weight) and particulate organic carbon (POC) show similar seasonality (Figure 1) with highest values in June and July but with still large fluxes through December. Winter fluxes were much lower. We selected samples 3, 7, 9, 13 and 17 for analysis of (chemically) free and total (i.e., saponifiable) fatty acids. These samples span the sampling period (June 1989 to May 1990) and include maximum dry weight/POC flux values (samples 3 and 7) as well as minimum values (samples 13 and 17). Care was also taken to avoid samples that were obviously strongly affected by high swimmer biomass (samples 10,12 , and 15).

\section{TTFA Flux}

TTFA fluxes (the sum of PTFA and DTFA fluxes) of (straight-chain) saturated, monounsaturated and diunsaturated fatty acids and of three pentadecanoic acid isomers are presented in Figures 2 and 3 . Values range between a few hundred nanograms per square meter per day per component (e.g., 6:0) and $60 \mu \mathrm{g} \mathrm{m}^{-2} \mathrm{~d}^{-1}$ (palmitic acid, 16:0), thus spanning more than 2 orders of magnitude.

Palmitic acid dominates the saturated fatty acid pattern, with myristic (14:0) and stearic acid (18:0) contributing significantly. The predominance of even-carbon chain lengths is also a characteristic feature. The ratio of odd- to even-numbered saturated fatty acids (up to 20 carbons) ranges between 0.07 and 0.10 for TTFA, which only slightly exceeds ratios of $0.02-0.08$ found in phytoplankton or zooplankton [Ackman and Sipos, 1965; Volkman et al., 1980]. Long-chain saturated fatty acids $(>20: 0)$ which are rarely produced in the marine environment are minor components with a slightly increased abundance of the 24:0 compound. This indicates a low or negligible input of terrestrial plant debris, which is rich in long-chain fatty acids (epicuticular waxes) with a chain length maximum at 24 or 26 carbons [Eglinton and Hamilton, 1967; Wannigama et al., 1981].

TTFA fluxes of monounsaturated and diunsaturated fatty acids are shown for even-carbon fatty acids only. TTFA flux is characterized by highest values for $\sum 18: 1$ which is probably mainly oleic acid (18:1 $\omega 9$ ), a typical zooplankton fatty acid [Sargent and Falk-Petersen, 1981]. The moderately abundant long-chain monounsaturated fatty acids $\Sigma$ 22:1 and $\sum 24: 1$ are indicative of zooplankton and higher marine organisms [Pascal and Ackman, 1976]. In general, the pattern is less clearly dominated by one compound. Some odd-carbon monounsaturated fatty acids $(\Sigma 15: 1, \Sigma$ 17:1, $\left.\sum 19: 1, \sum 21: 1, \sum 23: 1\right)$ were present, although at trace levels, as identified by their ITD-MS spectra. Odd-carbon number series of monounsaturated fatty acids have been reported to be of bacterial origin [Perry et al., 1979; Volkman et al., 1980].

For branched-chain fatty acids, TTFA fluxes are highest for isomers with odd-carbon numbers, e.g., 15:0 isomers. Similar abundances of anteisobranching and isobranching were observed. Branched-chain fatty acids represented one third to one half of the TTFA flux of $\sum$ 15:0 isomers. The ratio of branched to linear saturated fatty acids (up to 20 carbons) varies between 0.03 and 0.05 . Branched-chain fatty acids are usually suggested to be of bacterial origin and branched/linear ratios of up to 0.18 have been reported in laboratory cultures of marine bacteria [Perry et al., 1979; Volkman et al., 1980]. Other branched-chain fatty acids that were frequently found were iso- and anteiso-isomers of 17:0 and 19:0 and in some cases anteiso-16:0 and -18:0. From this considerable bacterial activity is indicated. However, biomarker patterns cannot distinguish between bacterial activity on sinking particles [Ducklow et al., 1985] and possible activity in sample cups, despite poisoning. Sodium azide can be a relatively poor biocide under some conditions [Lee et al., 1992]. Continued bacterial activity, especially in the high-flux period samples, may have occurred. 


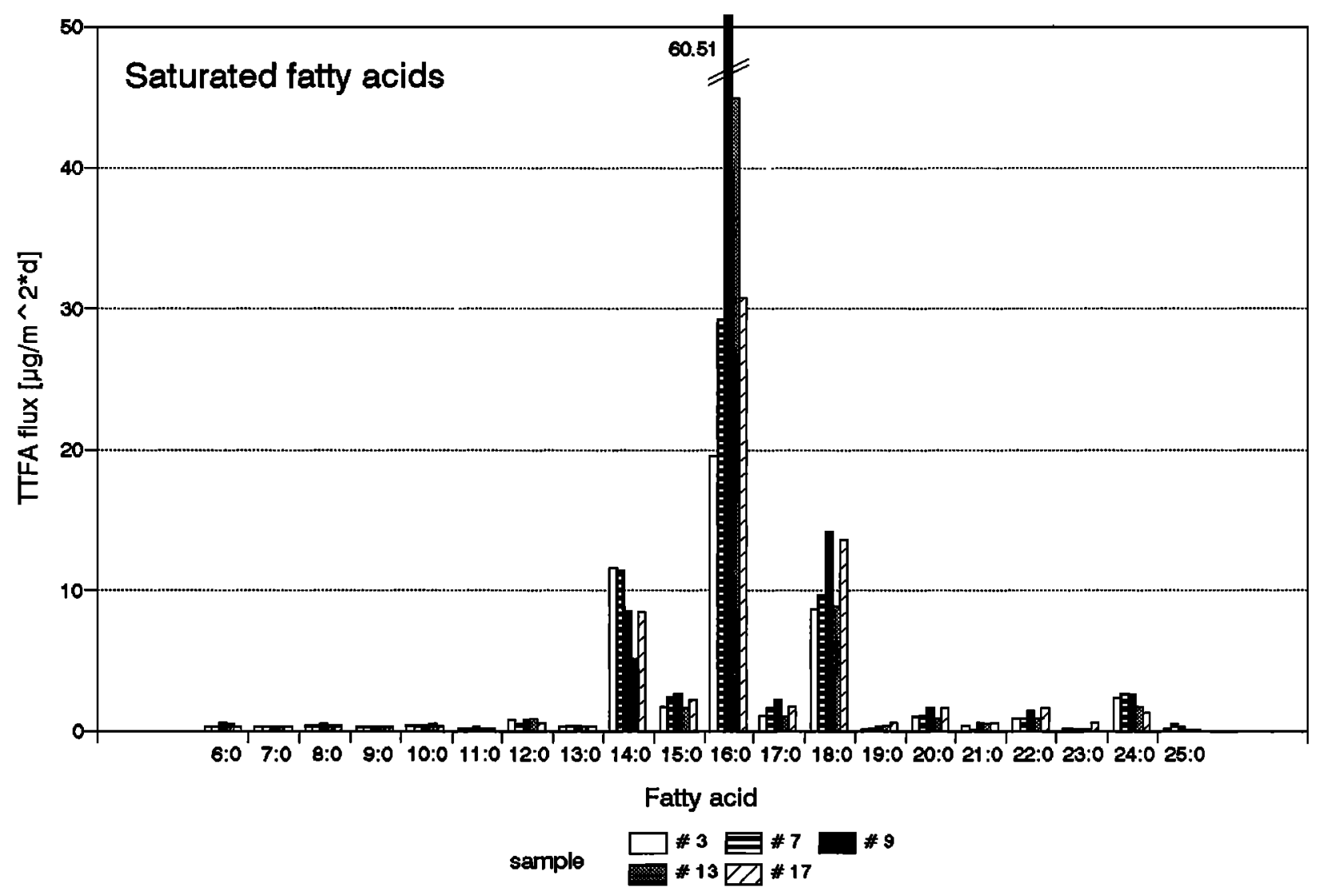

Figure 2. TTFA flux of straight-chain saturated fatty acids in micrograms per square meter per day. Sample numbers are defined in Figure 1.

\section{DTFA and PTFA Flux}

TTFA was calculated as the sum of DTFA and PTFA. The fluxes of the two compartments are presented separately in Table 1. Background concentrations of dissolved fatty acids in seawater were not measured and are not known for this area. However, spring surface samples from the Baltic Sea showed maximum concentrations of $\sum$ DFFA of the order of $1 \mu \mathrm{g} \mathrm{L}^{-1}$ [Osterroht, 1993] and dissolved fatty acids in water samples from Villefranche Bay, Mediterranean Sea, ranged between 0.53 and $11.36 \mu \mathrm{g} \mathrm{L}^{-1}$ [Goutx and Saliot, 1980], while $\sum$ DFFA concentrations in the supernatant solution range between 549 and $1500 \mu \mathrm{g} \mathrm{L}^{-1}$ ( $\sum$ DTFA of 553-5297 $\left.\mu \mathrm{g} \mathrm{L}^{-1}\right)$. From this it is very likely that particle-associated fatty acids were released into the dissolved phase. The question as to whether the high amount of dissolved fatty acids is a result of particle leaching in the sample cups or stems from a "halo" of highly concentrated water just around the particles or from intraparticulate water sinking with the particles cannot be answered. However, particleassociated substances would be treated as vertical flux regardless of type of fixation (matrix, "halo" water, or intraparticulate fluid). In terms of vertical fluxes the relevance of this phenomenon has two important aspects: the bulk flux of fatty acids and the flux of individual compounds in biomarker applications.

Concerning bulk flux data, the contribution of dissolved fatty acids ( $\sum$ DTFA) was found between $14.8 \%$ (sample 7 ) and $75.2 \%$ (sample 13) of $\sum$ TTFA fluxes (Figure 4). The analysis of only the particulate fraction will therefore not include up to $75 \%$ of the $\sum$ TTFA flux due to the contribution of $\sum$ DTFA. A comparison of the degree of dissolution with mass/POC flux data (Figure 1) reveals that the highest proportions of dissolved compounds are in low-flux period samples (13 and 17), whereas higher fluxes of particulate matter are characterized by a lower degree of dissolution. A key to understanding this may be the comparison of particle and supernatant concentrations of fatty acids. Concentration of $\sum$ PTFA in high flux periods is lower, ranging between 0.9 (sample 7) and 2.1 (sample 9) $\mu \mathrm{g} \sum$ PTFA mg ${ }^{-1}$ particle dry weight. Low-flux period samples are characterized by a higher range of particle concentrations between 4.2 (sample 17) and 5.8 (sample 13) $\mu \mathrm{g} \sum$ PTFA $\mathrm{mg}^{-1}$. Supernatant concentrations show a similar trend, for instance, high-flux period sample 7 with $0.6 \mu \mathrm{g} \sum$ DTFA $\mathrm{mL}^{-1}$ and low-flux period sample 13 with $5.3 \mu \mathrm{g} \sum$ DTFA mL ${ }^{-1}$. The ratio of particle to supernatant concentration is 1.1 (low-flux period sample 13) and 1.7 (high-flux period sample 7), with a total range from 1.1 to 2.3 (samples 7 to 17), thus indicating that the same effect rules the distribution between the two phases. Readsorption of previously dissolved fatty acids on the different amount of particulate phase in the cups is a possible explanation for such a similar distribution coefficient. The ratio could then be interpreted as a rough estimate of the adsorption coefficient of fatty acids on a sediment trap sample matrix. Only sample 3 does not fit into this range with a ratio of 0.3 .

An even more dramatic effect can be observed for the DTFA flux of individual fatty acid compounds (Table 1). The 

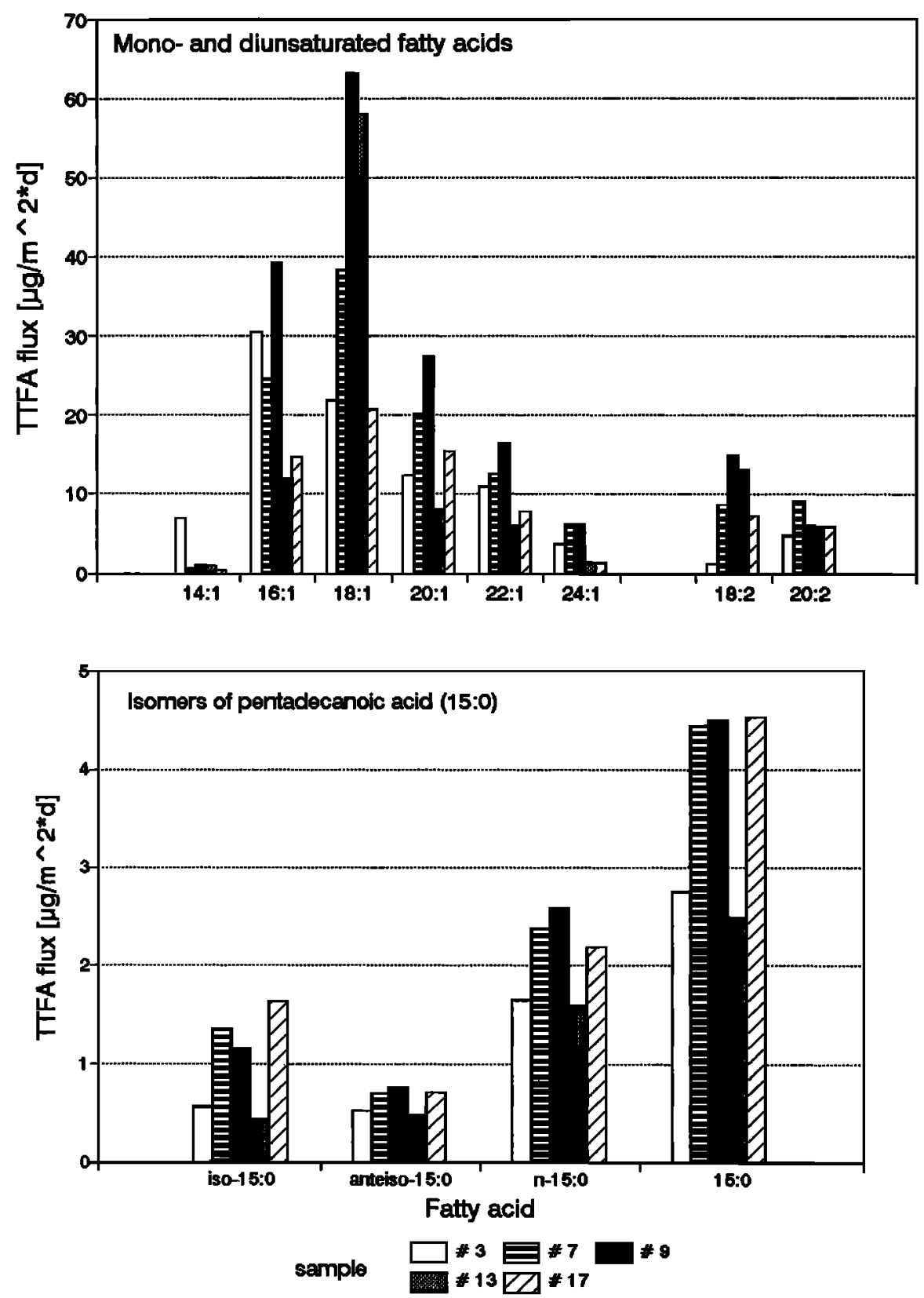

Figure 3. (top) TTFA flux of monounsaturated and diunsaturated fatty acids and (bottom) isomers of pentadecanoic acid in micrograms per square meter per day. Sample numbers are defined in Figure 1.

contributions of PTFA and DTFA to TTFA in sample 17 are shown as an example in Figure 5 for (straight-chain) saturated, monounsaturated and diunsaturated fatty acids and isomers of pentadecanoic acid. The contribution of DTFA fluxes to TTFA fluxes varies between $16 \%\left(\sum 22: 1\right)$ and $98 \%$ (23:0). The minor component safurated fatty acids (e.g. 6:0 and 23:0) show the highest percentage contribution in solution, whereas the more abundant fatty acids (e.g., 14:0, 16:0, 18:0) comprise a higher percentage of PTFA. The dissolved concentrations of the most abundant acid, palmitic acid, vary within an order of magnitude between the samples. It seems unlikely therefore that saturation of the supernatant could be the driving force, i.e., the limiting factor for the dissolution process of this most abundant fatty acid. Variation of supernatant concentrations is lowest (factors up to 2) at low concentration levels (6:0 to $13: 0,20: 0$ to $24: 0)$ and gradually increases with still moderate factors of up to 3 for 14:0 and 18:0. We think that the preferential dissolution of the less common fatty acids represents a matrix effect. The higher retention of typical algal fatty acids like 14:0, 16:0, and 18:0 and monounsaturated fatty acids may indicate that they have a different source than the almost completely dissolved uncommon fatty acids. This is supported by the observation that resuspension and lateral advection contributed significantly to the material collected (mass fluxes of the sediment trap $1000 \mathrm{~m}$ above are in general smaller). Resuspended material, which has been biochemically altered after contact with the seafloor, was likely trapped in very different proportions in the sample cups. The different origin and history of the particulate matter is probably connected with 
Table 1. PTFA and DTFA Fluxes

\begin{tabular}{|c|c|c|c|c|c|c|c|c|c|c|}
\hline \multirow[b]{2}{*}{ Fatty Acid } & \multicolumn{2}{|c|}{ Sample 3} & \multicolumn{2}{|c|}{ Sample 7} & \multicolumn{2}{|c|}{ Sample 9} & \multicolumn{2}{|c|}{ Sample 13} & \multicolumn{2}{|c|}{ Sample 17} \\
\hline & PTFA & DTFA & PTFA & DTFA & PTFA & DTFA & PTFA & DTFA & PTFA & DTFA \\
\hline $6: 0$ & 0.03 & 0.22 & 0.02 & 0.20 & 0.29 & 0.27 & 0.19 & 0.25 & 0.01 & 0.21 \\
\hline $7: 0$ & 0.02 & 0.22 & 0.01 & 0.20 & $\cdots$ & 0.25 & 0.01 & 0.24 & 0.01 & 0.20 \\
\hline 8:0 & 0.05 & 0.34 & 0.05 & 0.31 & 0.05 & 0.39 & 0.02 & 0.39 & 0.02 & 0.33 \\
\hline 9:0 & 0.06 & 0.24 & 0.04 & 0.21 & 0.06 & 0.26 & 0.01 & 0.28 & 0.01 & 0.21 \\
\hline 10:0 & 0.09 & 0.24 & 0.11 & 0.21 & 0.10 & 0.29 & 0.04 & 0.45 & 0.04 & 0.20 \\
\hline 11:0 & 0.01 & 0.17 & 0.02 & 0.15 & 0.02 & 0.19 & $\ldots$ & 0.19 & 0.01 & 0.16 \\
\hline $12: 0$ & 0.14 & 0.68 & 0.12 & 0.39 & 0.11 & 0.63 & 0.06 & 0.80 & 0.11 & 0.43 \\
\hline $13: 0$ & 0.09 & 0.21 & 0.18 & 0.18 & 0.12 & 0.23 & 0.06 & 0.23 & 0.05 & 0.21 \\
\hline $14: 0$ & 9.59 & 1.98 & 10.48 & 0.93 & 6.34 & 2.14 & 2.02 & 3.07 & 5.40 & 2.99 \\
\hline $15: 0$ & 0.76 & 0.89 & 1.88 & 0.50 & 1.61 & 0.97 & 0.53 & 1.05 & 0.80 & 1.39 \\
\hline $16: 0$ & 13.03 & 6.55 & 27.81 & 1.42 & 50.66 & 9.85 & 12.93 & 31.92 & 15.71 & 15.09 \\
\hline $17: 0$ & 0.42 & 0.65 & 1.08 & 0.49 & 1.52 & 0.72 & 0.31 & 0.72 & 0.89 & 0.86 \\
\hline 18:0 & 3.09 & 5.53 & 6.49 & 3.15 & 9.58 & 4.61 & 2.72 & 6.06 & 6.57 & 7.03 \\
\hline $19: 0$ & 0.10 & $\operatorname{tr}$ & 0.20 & $\operatorname{tr}$ & 0.26 & tr & 0.06 & 0.34 & 0.27 & 0.30 \\
\hline 20:0 & 0.30 & 0.66 & 0.62 & 0.42 & 0.94 & 0.61 & 0.19 & 0.68 & 0.54 & 1.05 \\
\hline 21:0 & 0.04 & 0.34 & 0.09 & $\mathrm{tr}$ & 0.18 & 0.38 & 0.03 & 0.40 & 0.03 & 0.50 \\
\hline 22:0 & 0.31 & 0.60 & 0.49 & 0.42 & 0.76 & 0.64 & 0.13 & 0.74 & 0.16 & 1.44 \\
\hline 23:0 & 0.02 & 0.16 & 0.16 & tr & 0.17 & $\operatorname{tr}$ & 0.03 & $\operatorname{tr}$ & 0.01 & 0.60 \\
\hline $24: 0$ & 0.58 & 1.74 & 1.86 & 0.73 & 1.32 & 1.24 & 0.27 & 1.41 & 0.09 & 1.25 \\
\hline $25: 0$ & 0.07 & 0.07 & 0.35 & 0.07 & 0.16 & 0.07 & 0.06 & tr & 0.03 & $\mathrm{tr}$ \\
\hline $14: 1$ & 0.10 & 6.85 & 0.15 & 0.54 & 0.21 & 0.85 & 0.04 & 0.96 & 0.05 & 0.44 \\
\hline $16: 1$ & 13.47 & 17.02 & 21.88 & 2.65 & 34.37 & 4.91 & 5.13 & 6.80 & 11.22 & 3.47 \\
\hline $18: 1$ & 17.96 & 3.90 & 35.46 & 2.97 & 54.82 & 8.40 & 11.19 & 46.90 & 14.15 & 6.59 \\
\hline $20: 1$ & 8.77 & 3.57 & 19.39 & 0.74 & 25.11 & 2.30 & 2.77 & 5.36 & 12.05 & 3.43 \\
\hline $22: 1$ & 10.91 & 0.19 & 12.06 & 0.46 & 15.27 & 1.15 & 2.73 & 3.27 & 6.55 & 1.28 \\
\hline $24: 1$ & 3.61 & $\mathrm{tr}$ & 6.15 & tr & 6.16 & 0.03 & 1.04 & 0.42 & 1.49 & $\mathrm{tr}$ \\
\hline $18: 2$ & 1.25 & 0.09 & 2.45 & 6.14 & 2.99 & 12.07 & 0.45 & 12.58 & 0.65 & 6.67 \\
\hline $20: 2$ & 0.88 & 3.95 & 5.82 & 3.28 & 1.97 & 4.08 & 0.25 & 5.57 & 1.49 & 4.49 \\
\hline i15:0 & 0.34 & 0.23 & 1.16 & 0.20 & 0.89 & 0.27 & 0.12 & 0.32 & 1.30 & 0.34 \\
\hline a15:0 & 0.18 & 0.34 & 0.44 & 0.26 & 0.41 & 0.35 & 0.10 & 0.37 & 0.29 & 0.42 \\
\hline $\mathrm{i}+\mathrm{a} 17: 0$ & 0.20 & 0.53 & 2.02 & 0.42 & 2.29 & 0.61 & 0.23 & 0.66 & 0.92 & n.a. \\
\hline$\Sigma$ & 86.47 & 58.16 & 159.04 & 27.64 & 218.742 & 58.76 & 43.72 & 132.43 & 80.92 & 61.58 \\
\hline
\end{tabular}

PTFA, particulate total fatty acids; DTFA, dissolved total fatty acids. Fluxes are in micrograms per square meter per day. Sample numbers are defined in Figure 1.

different biomarker patterns. $\sum$ TTFA particle concentrations, calculated on the basis of the remaining particle dryweight, are 20 times higher in sample 13 than in sample 7. Assuming that dissolved total fatty acids stem completely

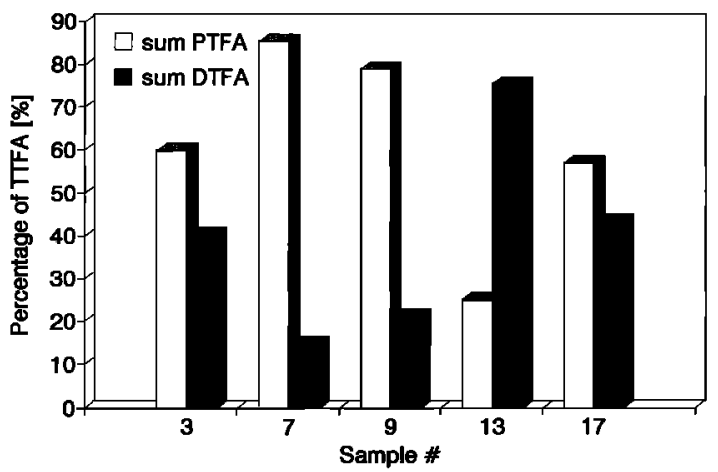

Figure 4. Percentage flux contribution of $\Sigma$ PTFA and $\Sigma$ DTFA to $\Sigma$ TTFA. PTFA and DTFA denote particulate and dissolved total fatty acids derived from saponification of extracts. $\sum$ PTFA and $\sum$ DTFA represent the sum of individual components. TTFA = DTFA + PTFA. Sample numbers are defined in Figure 1. from dissolution of particulate matter and that loss of particle dry weight due to dissolution/leaching processes is negligible, these concentrations can be taken as representing the original particle concentrations of $\sum$ TTFA. Thus obviously significant changes in the type of material occur. Another explanation could be a different type of biochemical fixation or incorporation of these substances in the matrix, e.g., cell surfaces, cell organelles, aggregates etc., which results in different release kinetics.

The relative contributions of DTFA and PTFA to TTFA are different for monounsaturated and diunsaturated fatty acids. In general, they are characterized by a decreasing dissolved fraction with increasing chain length. This may reflect the effect of decreasing polarity (water solubility) in a homologous series of unsaturated fatty acids.

The degree of dissolution in sediment trap samples was found to be high but variable. Variations may partly reflect the different type of trapped material or biochemical fixation in the matrix, especially in the light of resuspension of particulate matter from the seabed. There is also evidence from distribution coefficients that the degree of dissolution is ruled by a readsorption effect. The massive amounts of fatty acids are not likely to be artifacts of the sample preparation. Compared with filtration procedures and rotary splitting, 

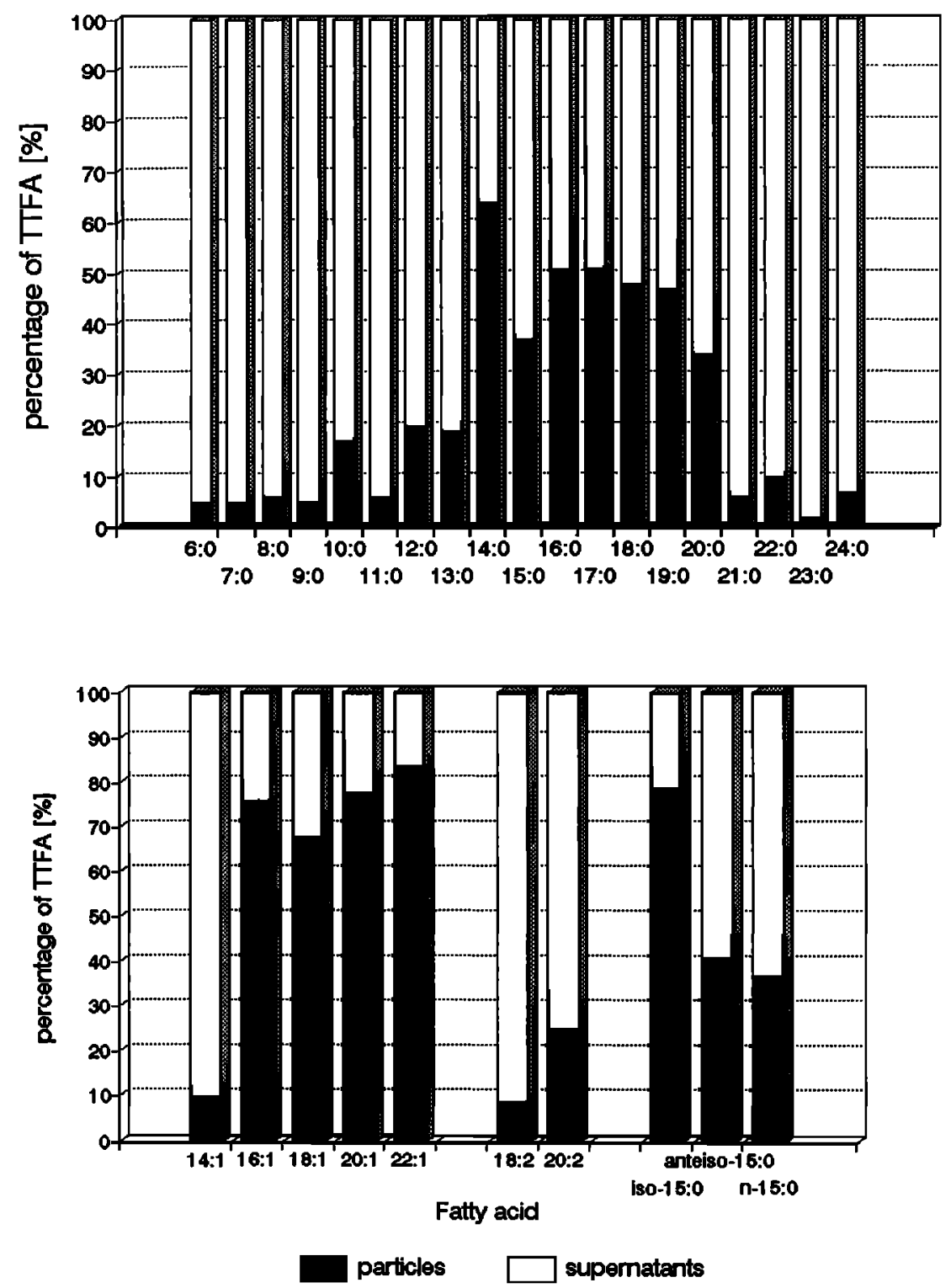

Figure 5. Percentage flux contribution of PTFA and DTFA to TTFA in sample 17: (top) straight-chain saturated fatty acids, and (bottom) monounsaturated and diunsaturated fatty acids and isomers of pentadecanoic acid. TTFA = DTFA + PTFA.

where the delicate equilibrium between the two phases may be disturbed with a relatively large volume of splitting water, centrifugation seems to be the mildest sample handling. None of these sample handling procedures can completely exclude the release of particle-associated organics.

The effect of swimmers that may have been trapped but not removed from the samples in general is difficult to evaluate. Wax ester analyses, which have been carried out with the particulate phase only, show only trace amounts of wax esters in samples 9,13 , and 17 and moderate total wax ester fluxes in samples 3 and $7\left(3-4 \mu \mathrm{g} \mathrm{m}^{-2} \mathrm{~d}^{-1}\right.$; maximum values in other samples are $50-60 \mu \mathrm{g} \mathrm{m}^{-2} \mathrm{~d}^{-1}$ ) with a high percentage of saturated and monounsaturated wax esters. Wax esters found in the marine environment are believed to be almost entirely zooplankton in origin since they are rarely produced in phytoplankton [Lee et al., 1971]. They are the dominant class of lipids in calanoid copepods [Lee et al., 1971] and are still abundant in various other zooplankton species (e.g., Thysanoessa inermis) [Sargent and FalkPetersen, 1981]. In copepods, considerable amounts of polyunsaturated wax esters are present [Kattner and Fricke, 1986]. Preferred uptake of polyunsaturated fatty acids by zooplankton organisms with corresponding decreased concentrations in fecal pellets has been reported for fatty acids [Neal et al., 1986; Harvey et al., 1987]. The same effect was found for wax esters in fecal pellets (C. Thomsen, personal communication, 1993. In this study, samples 10,12 , and 15 contained a number of swimmers and thus are as expected the only samples dominated by high amounts of polyunsaturated wax esters. The wax ester patterns of the other samples are characterized by a clear predominance of saturated and monounsaturated wax esters and are similar to those previously described for sediment trap material [Wakeham, 1982, 1985]. This indicates that typical fecal pellet material rather than swimmers was trapped. Using this criterion, samples $3,7,9,13$, and 17 were chosen to avoid 
massive artifacts from swimmers. Although a biasing effect of swimmers cannot be excluded, we consider it not significantly responsible for the high concentration of dissolved fatty acids. The fatty acid inventory of zooplankton swimmers includes relatively high amounts of polyunsaturated fatty acids or fatty acid derivatives [e.g., Kattner and Krause, 1989]. Disintegration and extraction of swimmers would thus strongly bias fluxes of polyunsaturated fatty acids but could not explain the massive release of common algal fatty acids into solution.

Dissolved organic matter artifacts caused by continued bacterial activity in the sample cups are another point which has to be discussed. Observed bacterial biomarker fatty acids show that bacterial activity occurred either before the material entered the trap of afterward. However, bacterial activity indicated by the presence of branched-chain fatty acids and a homologous series of odd-carbon saturated and monounsaturated fatty acids is similar to that reported from other sediment trap experiments [e.g., Reemtsma et al., 1990]. Further, the flux contribution (TTFA values) of branched-chain fatty acids to $\Sigma$ TTFA is highest in sample 7 (2.3\%) and lowest in sample $13(1 \%)$. This is contradictory to the observed degree of dissolution in these samples.

High soluble pools also were found for trace elements (up to almost $100 \%$ of the total for certain elements [Duinker and Kremling, 1990; U. Schüssler, personal communication, 1993]) and amino acids (1-10\%) in sediment trap samples [Duinker and Kremling, 1990]. Further supporting evidence for dissolution/leaching processes was reported for different parameters [von Bodungen et al., 1991]. Average values for the amount of dissolution of particulate fatty acids into supernatants cannot be estimated from these results and would be inadequate for discussion of individual (biomarker) substances anyway. Concentration levels, polarity, amount of particulate phase, matrix origin, matrix fixation, and other properties are likely to affect the degree of dissolution of individual compounds.

\section{DFFA and PFFA Flux}

Free fatty acids will be considered only briefly in this discussion. They may represent artifacts resulting from cellolysis (by action of lipases from damaged cells), but they are also normal components of the lipid pool in tissues [Chapman, 1969; Parrish, 1988]. $\Sigma$ DFFA and $\Sigma$ PFFA values (Figure 6) show that an even higher proportion of free fatty acids undergoes dissolution and leaching than total fatty acids (Figure 4). $\sum$ DFFA ranges between $24.9 \%$ (sample 7) and 88.4\% (sample 13) of $\sum$ TFFA. Particle and supernatant concentrations of free fatty acids show the same trends as were discussed for total fatty acids, with higher concentrations in low-flux period samples (e.g., sample 13: $3.0 \mu \mathrm{g} \sum$ DFFA mL ${ }^{-1} ; 1.3 \mu \mathrm{g} \sum$ PFFA $\mathrm{mg}^{-1}$ particle dry weight), and lower concentrations in high-flux period samples (e.g., sample 7: $0.4 \mu \mathrm{g} \sum$ DFFA $\mathrm{mL}^{-1} ; 0.3 \mu \mathrm{g} \sum$ PFFA $\mathrm{mg}^{-1}$ particle dry weight). The concentration ratio ranges between 4.3 and 13.9. Again, sample 3 reflects a different situation with a ratio of only 0.2 . These results may refiect the much higher polarity and therefore water solubility of free carboxylic acids compared with many natural derivatives like methyl, ethyl, and wax esters. Again the results indicate that a major effect like readsorption determines the distribution of compounds between the two compartments.

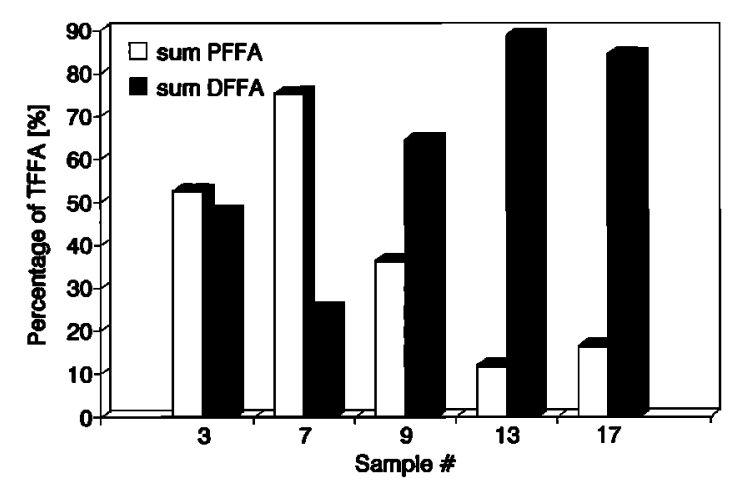

Figure 6. Percentage flux contribution of $\sum$ PFFA and $\Sigma$ DFFA to $\sum$ TFFA. PFFA and DFFA denote particulate and dissolved free fatty acids. $\sum$ PFFA and $\sum$ DFFA represent the sum of individual components. TFFA $=$ DFFA + PFFA. Sample numbers are defined in Figure 1.

\section{Conclusions}

This study has shown that dissolution and leaching can result in a significant bias to flux calculations if dissolved components of sediment trap material are not measured. Future applications of sediment traps in flux studies should quantify or at least estimate the transition of particleassociated compounds into solution by degradation and leaching processes in the cups. Analysis of supernatants is indispensable for the assessment of reliable flux data. We have to either ensure that dissolution is negligible or, alternatively, quantify dissolved substances. Time series sediment trap technology must include tight sample cups in the revolving unit. Dissolution of particles can generate high concentrations of analytes in supernatants. If cups are not sufficiently tight when removed from the funnel, no equilibration between particles and supernatants will occur, and continuous loss of material by diffusion to the surrounding seawater is possible. The effect of commonly used procedures like filtration, centrifugation, and rotary splitting on dissolution equilibria during sample processing should be carefully evaluated.

Acknowledgments. We thank the captain and crew of R/V Meteor and R/V Poseidon for the skilfull work of deploying and recovering the mooring array. We also very much appreciate the contribution of U. Schüssler to planning of the mooring as well as splitting and pretreatment of samples. The project "Partikelfluss im Nordatlantik, organische Spurenstoffe" was funded by the German Research Council grant DFG Du 147/1-2. Last but not least, we would like to express our thanks to the two anonymous reviewers, who with their good ideas contributed greatly to this publication.

\section{References}

Ackman, R. G., and J. C. Sipos, Isolation of saturated fatty acids of some marine lipids with particular reference to normal oddnumbered fatty acids and branched chain fatty acids, Comp. Biochem. Physiol., 15, 445-456, 1965.

Baker, E. T., H. B. Milburn, and D. A. Tennant, Field assessment of sediment trap efficiency under varying flow conditions, J. Mar. Res., 46, 573-592, 1988.

Butman, C. A., W. D. Grant, and K. D. Stolzenbach, Predictions of sediment trap biases in turbulent flows: A theoretical analysis based on observations from the literature, J. Mar. Res., 44, 601-644, 1986. 
Chapman, D., Introduction to Lipids, 144 pp., McGraw-Hill, New York, 1969 .

Collier, R. M., and J. M. Edmond, The trace element geochemistry of marine biogenic particulate matter, Prog. Oceanogr., 13, 113-119, 1984.

Currie, B. R., and R. B. Johns, Lipids as indicators of the origin of organic matter in fine marine particulate matter, Aust. J. Mar. Freshwater Res., 39, 371-383, 1988.

De Baar, H. J. W., J. W. Farrington, and S. G. Wakeham, Vertical flux of fatty acids in the North Atlantic Ocean, J. Mar. Res., 4I, 19-41, 1983.

Ducklow, H. W., S. M. Hill, and W. D. Gardner, Bacterial growth and the decomposition of particulate organic carbon collected in sediment traps, Cont. Shelf Res., 4, 445-464, 1985.

Duinker, J. C., and K. Kremling, Report to German Research Council Project "Partikelfluss im Nordatlantik, chemische Spurenstoffe", Inst. für Meereskd., Univ. Kiel, Kiel, Germany, 1990.

Eglinton, G., and R. J. Hamilton, Leaf epicuticular waxes, Science, 156, 1322-1335, 1967.

Gardner, W. D., The effect of tilt on sediment trap efficiency, Deep Sea Res., 32, 349-361, 1985.

Gardner, W. D., K. R. Hinga, and J. Marra, Observations on the degradation of biogenic material in the deep ocean with implications on accuracy of sediment trap fluxes, J. Mar. Res., 41, 195-214, 1983.

Goutx, M., and A. Saliot, Relationship between dissolved and particulate fatty acids and hydrocarbons, chlorophyll $a$ and zooplankton biomass in Villefranche Bay, Mediterranean Sea, Mar. Chem., 8, 299-318, 1980.

Gundersen, K., and P. Wassmann, Use of chloroform in sediment traps: Caution advised, Mar. Ecol. Prog. Ser., 64, 187-195, 1990.

Gust, G., R. H. Byrne, R. E. Bernstein, P. R. Betzer, and W. Bowles, Particle fluxes and moving fluids: Experience from synchronous trap collections in the Sargasso Sea, Deep Sea Res., 39, 1071-1083, 1992.

Harvey, H. R., G. Eglinton, S. C. M. O'Hara, and E. D. S. Corner, Biotransformation and assimilation of dietary lipids by Calanus feeding on a dinoflagellate, Geochim. Cosmochim. Acta, 51, 3031-3040, 1987.

Honjo, S., S. J. Manganini, and J. J. Cole, Sedimentation of biogenic matter in the deep ocean, Deep Sea Res., 29, 609-625, 1982.

Honjo, S., D. W. Spencer, and W. D. Gardner, A sediment trap intercomparison experiment in the Panama Basin, 1979, Deep Sea Res., 39, 333-358, 1992.

Kattner, G., and H. S. G. Fricke, Simple gas-liquid chromatographic method for the simultaneous determination of fatty acids and alcohols in wax esters of marine organisms, J. Chromatogr., $361,263-268,1986$.

Kattner, G., and M. Krause, Seasonal variations of lipids (wax esters, fatty acids and alcohols) in calanoid copepods from the North Sea, Mar. Chem., 26, 261-275, 1989.

Kim, R. K., M. K. Hahn, A. Zlatkis, E. C. Horning, and B. S. Middleditch, Simultaneous gas chromatography of volatile and non-volatile carboxylic acids as tert.-butyldimethylsilyl derivatives, J. Chromatogr., 468, 289-301, 1989.

Knauer, G. A., and V. Asper (Eds.), Sediment trap technology and sampling, U.S. JGOFS Rep. 10, 94 pp., U.S. Joint Global Ocean Flux Study, Woods Hole, Mass., 1989.

Knauer, G. A., D. M. Karl, J. H. Martin, and C. N. Hunter, In situ effects of selected preservatives on total carbon, nitrogen and metals collected in sediment traps, J. Mar. Res., 42, 445-462, 1984.

Lee, C., J. I. Hedges, S. G. Wakeham, and N. Zhu, Effectiveness of various treatments in retarding microbial activity in sediment trap material and their effects on the collection of swimmers, Limnol. Oceanogr., 37, 117-130, 1992.

Lee, R. F., J. C. Nevenzel, and G.-A. Paffenhöfer, Importance of wax esters and other lipids in the marine food chain: Phytoplankton and copepods, Mar. Biol., 9, 99-108, 1971.

Mayzaud, P., J. P. Chanut, and R. G. Ackman, Seasonal changes of the biochemical composition of marine particulate matter with special reference to fatty acids and sterols, Mar. Ecol. Prog. Ser., 56, 189-204, 1989.

Michaels, A. F., M. W. Silver, M. M. Gowing, and G. A. Knauer, Cryptic zooplankton "swimmers" in upper ocean sediment traps, Deep Sea Res., 37, 1285-1296, 1990.

Neal, A. C., F. G. Prahl, G. Eglinton, S. C. M. O'Hara, and E. D. S. Corner, Lipid changes during a planktonic feeding sequence involving unicellular algae, Elminius nauplii and adult Calanus, $J$. Mar. Biol. Assoc. U.K., 66, 1-13, 1986.

Osterroht, C., Extraction of dissolved fatty acids from sea water, Fresenius J. Anal. Chem., 345, 773-779, 1993.

Parrish, C. C., Dissolved and particulate marine lipid classes: A review, Mar. Chem., 23, 17-40, 1988.

Pascal, J. C., and R. G. Ackman, Long chain monoethylenic alcohol and acid isomers in lipids of copepods and capelin, Chem. Phys. Lipids, 16, 219-223, 1976.

Perry, G. J., J. K. Volkman, R. B. Johns, and H. J. Bavor, Jr., Fatty acids of bacterial origin in contemporary marine sediments, Geochim. Cosmochim. Acta, 43, 1715-1725, 1979.

Reemtsma, T., B. Haake, V. Ittekott, R. R. Nair, and U. H. Brockmann, Downward flux of particulate fatty acids in the central Arabian Sea, Mar. Chem., 29, 183-202, 1990.

Sargent, J. R., and S. Falk-Petersen, Ecological investigations on the zooplankton community in Balsfjorden, northern Norway: Lipids and fatty acids in Meganyctiphanes norvegica, Thysanoessa raschi and T. inermis during midwinter, Mar. Biol., 62, 131-137, 1981.

Sicre, M.-A., J.-L. Paillasseur, J.-C. Marty, and A. Saliot, Characterization of seawater samples using chemometric methods applied to biomarker fatty acids, Org. Geochem., 12, 281-288, 1988.

Volkman, J. K., R. B. Johns, F. T. Gillan, G. J. Perry, and H. J. Bavor, Jr., Microbial lipids of an intertidal sediment, I, Fatty acids and hydrocarbons, Geochim. Cosmochim. Acta, 44, 11331143,1980

von Bodungen, B., M. Wunsch, and H. Fürderer, Sampling and analysis of suspended and sinking particles in the northern North Atlantic, in Marine Particles: Analysis and Characterization, Geophys. Monog. Ser., vol. 63, edited by D. C. Hurd and D. W. Spencer, pp. 47-56, AGU, Washington, D. C., 1991.

Wakeham, S. G., Organic matter from a sediment trap experiment in the equatorial North Atlantic: Wax esters, steryl esters, triacylglycerols, and alkyldiacylglycerol, Geochim. Cosmochim. Acta, 46, 2239-2257, 1982.

Wakeham, S. G., Wax esters and triacylglycerols in sinking particulate matter in the Peru upwelling area $\left(15^{\circ} \mathrm{S}, 75^{\circ} \mathrm{W}\right)$, Mar. Chem., $17,213-235,1985$.

Wakeham, S. G., and J. A. Beier, Fatty acid and sterol biomarkers as indicators of particulate matter source and alteration processes in the Black Sea, Deep Sea Res., 38, 943-968, 1991.

Wakeham, S. G., and E. A. Canuel, Organic geochemistry of particulate matter in the eastern tropical North Pacific Ocean: Implications for particle dynamics, J. Mar. Res., 46, 183-213, 1988.

Wakeham, S. G., and C. Lee, Organic geochemistry of particulate matter in the ocean: The role of particles in oceanic sedimentary cycles, Org. Geochem., 14, 83-96, 1989.

Wakeham, S. G., C. Lee, J. W. Farrington, and R. B. Gagosian, Biogeochemistry of particulate organic matter in the oceans: Results from sediment trap experiments, Deep Sea Res., 31, 509-528, 1984.

Wannigama, G. P., J. K. Volkman, F. T. Gillan, P. D. Nichols, and R. B. Johns, A comparison of lipid component of the fresh and dead leaves and pneumatophores of the mangrove Avicennia marina, Phytochemistry, 20, 659-666, 1981.

J. C. Duinker, A. Körtzinger, G. Petrick, and D. E. Schultz-Bull, Department of Marine Chemistry, Institut für Meereskunde an der Universität Kiel, Düsternbrooker Weg 20, 24105 Kiel, Germany.

(Received February 9, 1993; revised September 8, 1993; accepted October 1, 1993.) 